\title{
Cryolipolysis: patient selection and special considerations
}

This article was published in the following Dove Press journal: Clinical, Cosmetic and Investigational Dermatology

\section{Patricia Froes Meyer Julio Davi Costa e Silva ${ }^{2}$ Liliane Santos de Vasconcellos ${ }^{3}$ Eneida de Morais Carreiro ${ }^{4}$ Rodrigo Marcel Valentim da Silva ${ }^{5,6}$}

'Department of Physiotherapy, Potiguar University, Natal, Brazil; ${ }^{2}$ Department of Physiotherapy, Potiguar University - UnP, Natal, Brazil; ${ }^{3}$ Department of Physical Therapy, Potiguar University - UnP Natal, Rio Grande do Norte, Brazil; ${ }^{4}$ Center University of Rio Grande do Norte, Physiotherapy Department, Natal, Brazil; ${ }^{5}$ Estácio de Sá University, Physiotherapy Department, Natal, Brazil; ${ }^{6}$ Mauricio de Nassau College, Physiotherapy Department, Natal, Brazil
Correspondence: Patricia Froes Meyer Universidade Potiguar, Cep: 59020160, Maxaranguape St, 550/2603, Tirol, Natal, Rio Grande do Norte 59020160, Brazil Tel +55 8499826469

Email patrícia.froesmeyer@gmail.com

\begin{abstract}
Cryolipolysis is considered a safe and effective procedure, with high patient satisfaction rates, especially when compared to other procedures for localized adiposity, such as high-intensity focused ultrasound and shock waves. Although this statement is present in the literature, the importance of the selection of suitable patients for this type of treatment is not well known. The objective of this study was to discuss the criteria to be considered in the selection of patients who are candidates for cryolipolysis and assess their profile regarding their anthropometric data, age, skin characteristics, cutaneous sensitivity, and risk pathologies for this type of treatment. Assessing the amount of localized adiposity requires safe and validated methods that are significant in measuring results. The aim is to achieve success in the process of reducing adiposity guaranteeing patient satisfaction and assurance of results.
\end{abstract}

Keywords: adiposity, dermatologic physical therapy, cryolipolysis

\section{Introduction}

Different clinical observations have shown that the adipose tissue is sensitive to cooling, promoting the development of inflammation responses, apoptosis, and consequent reduction of localized adiposity. The premise that the adipose tissue is the cellular formation most susceptible to cooling when compared to other cells has promoted interest in the study of different cooling techniques to reduce localized adiposity. ${ }^{1}$

It is suggested that in cryolipolysis, the localized cooling triggers apoptosis of adipocytes, which causes an inflammatory response and promotes slow cell macrophagy. ${ }^{1}$ To this end, the applicator is placed on the area to be treated in order to gradually extract heat until the target temperature is reached $\left(\mathrm{eg},-10^{\circ} \mathrm{C}\right.$ to $\left.-1^{\circ} \mathrm{C}\right)$ for a predetermined period. ${ }^{2}$

After a single intervention, the apoptosis of the adipocytes generates a collagen increase in the adipose tissue related to the process of lobular panniculitis and thickening of the interlobular fibrous septa that occur over several months, resulting in fat layer thickening reduction. ${ }^{2}$

The assisted cooling system selectively acts on the adipocytes, generating inflammation, which results in the death of the adipose cell. ${ }^{3}$ The lipid that was previously contained by the adipocytes will be metabolized and eliminated by the body within around 4 months, and it will be possible to see $20 \%-26 \%$ fat layer reduction of the treated area. However, 1 month after the application, clinical results may already be seen. ${ }^{4}$

It is understood that the function of a cryolipolysis apparatus is to reduce the amount of localized adipose tissue through apoptosis induction, that is, fat cells death, 
using a selective and controlled cooling system. Some cryolipolysis devices differ in temperature generation, handling, and application technique. The applicators are connected to the skin and, through the suction mechanism, they cool the dermis and hypodermis tissue using the cooling system of the Peltier cells, located inside the applicator. ${ }^{5,6}$

Cryolipolysis is considered a safe and effective procedure, with high patient satisfaction rates, especially where compared to other procedures for localized adiposity, such as high-intensity focused ultrasound and shock waves. ${ }^{7,8}$ Although this statement is given in the literature, the importance of selection of patients suitable for this type of treatment is not well known. Cryolipolysis is not an indication for the treatment of obese individuals, but is specific to those who have discrete localized fat that persists despite diets and physical activities. ${ }^{9,10}$ Therefore, relevant criteria should be considered before cryolipolysis treatment, such as patients' anthropometric data, age, skin characteristics, normal sensitivity, and risk pathologies. Assessing the amount of localized adiposity requires safe and validated methods that are important for result measurement.

\section{Cryolipolysis candidate patient profile}

In the study by Meyer et al, ${ }^{10}$ at the end of the data collection of a group of patients subjected to abdominal cryolipolysis, it was noticed that, despite weight variations, the mean deviation was not statistically significant, which corroborates with the previous statement that cryolipolysis is not an indication for obese patients, but rather for localized adiposity of patients who have little or no change in body weight. This results was also in agreement with that of Ferraro et al, ${ }^{9}$ who stated that the results of cryolipolysis are more visible in patients with discrete localized fat and that it is not very effective in obese patients. Therefore, this is a critical point to be considered in the evaluation and selection of treatment candidates. ${ }^{9}$

It is also suggested that there is a less efficient response in patients who had greater amount of adipose tissue, which may be explained by the inadequate temperature or by the difficulty that the applicator cup found in drawing a minimum amount of tissue for the treatment, both due to the amount of fat. Another cause of difficulty of use of the applicator cup is the presence of fibrosis, that cause resistance of the skin in the zone where it performs the suction. Stevens and Bachelor $^{11}$ observed that areas with fibrous fat, such as the thigh region, present a challenge, as this type of fat is not easily drawn by vacuum suction.

\section{Age: when is the patient able to undergo cryolipolysis?}

There is no age limitation for cryolipolysis mentioned in literature. Currently, the presence of localized adiposity in children and adolescents, the result of poor diets and sedentary lifestyle, is noticed every day. The candidate for treatment should be in good health, have no history of neurological or orthopedic problems, and should present normal renal function. One study recommended the individuals to be aged between 13 and 16 years old, to analyze the effect of cryolipolysis in comparison to laser lipolysis in adolescents. ${ }^{12}$ Despite the age, there was good adherence to the treatment with satisfactory results, even with a small analyzed sample.

\section{Skin characteristics and skin sensitivity}

According to the study of Mostafa and Elshafey, ${ }^{12}$ cryolipolysis is considered a safe procedure and may be applied to all skin types without any risk, even with recurrent applications.

Klein et a $1^{13}$ observed skin tightness as a result of cryolipolysis treatment in patients with flaccidity, and even patients who had a significant reduction in fat volume did not present skin flaccidity. Instead, after 4 months of treatment, the firm skin adhered well to its new bodily contours. ${ }^{11}$ Many authors state that the mechanism by which cryolipolysis induces skin tightness is not well understood but may be the result of stimulated collagen production, new elastin formation, fibrosis, or tissue compaction. It is assumed that the presence of fibrosis observed in these studies occurs for an improvement in skin flaccidity. ${ }^{3,13}$

In their study, Bernstein and Bloom et $\mathrm{al}^{14}$ observed through ultrasound images that there was a reduction in the fat layer after a single application. In previous studies of abdominal adiposity cryolipolysis, the presence of fibrosis in the adipose tissue before and 7, 15, and 45 days after the treatment was observed through the ultrasound images. ${ }^{10,15}$

Figure 1 shows the ultrasound images of one of the patients at 3 time points: before and 30 and 60 days after the treatment. It is possible to see the physiological reactions induced by cryolipolysis, such as the inflammatory process, which appears as a whitish area, and fibrosis, caused by adipocyte septa thickening. ${ }^{10}$

It was also possible to observe the destruction of adipocyte membranes and the presence of fibrosis upon histological analysis. In a study by Zelickson et al, ${ }^{3}$ which was carried out with pigs to study fat layer reduction of layer adipose through cryolipolysis, the loss of adipocytes and 
A

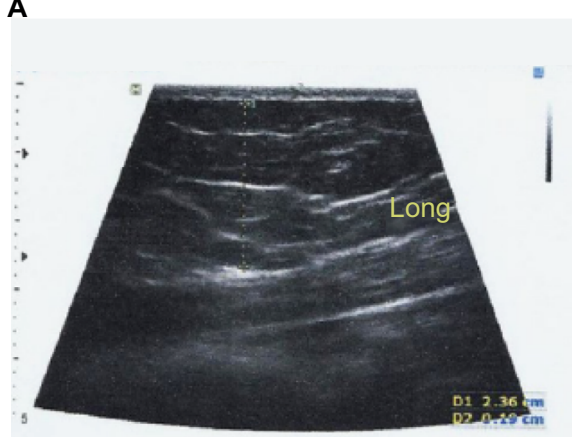

B

C

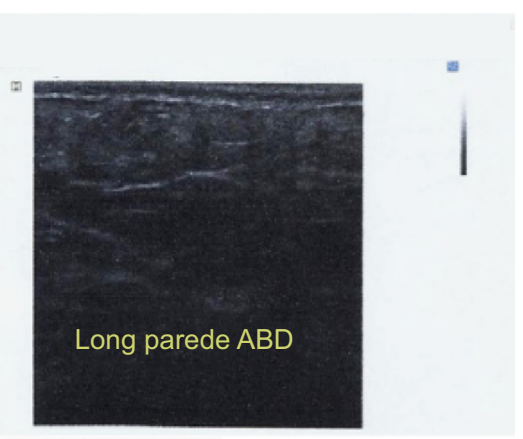

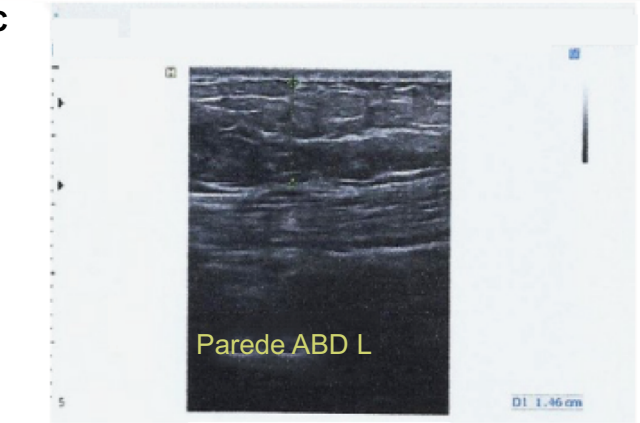

Figure I Ultrasonography of one of the participants, the first taken before cryolipolysis (A) and the following taken 30 (B) and 60 days (C) later.

local thickening of fibrous septae were verified through of histological analysis.

In the study by Meyer et al, ${ }^{15}$ the application of cryolipolysis was performed in the abdominal region in a volunteer. This patient then underwent abdominoplasty surgery and the removed tissue was histologically analyzed. Cryolipolysis was done 45 days before surgery. ${ }^{15}$

Regarding the histological record, normal appearance of adipose tissue and adjacent tissues of the untreated region were observed (Figure 2A). It was possible to observe the destruction of adipocyte membranes and the presence of fibrosis in adipose tissue in detail (Figure 2B).

Regarding cutaneous sensitivity, it is important to consider that the sensorial integrity of the area to be treated is a patient exclusion criterion if not present, as due to the cold temperature induction, sensitivity control is fundamental. Dierickx et $\mathrm{al}^{7}$ reported that changes in local sensitivity may occur after cryolipolysis, with usual hyposensitivity, but the problem does not persist 3 months after application. According to Coleman et al, ${ }^{16}$ there was a transient reduction of sensory function in a proportion of the individuals (neurological evaluation), which was restored in $<4$ weeks. There was no change in nerve fibers structure and no skin damage. ${ }^{16}$

\section{Localized adiposity assessing methods}

Assessing localized adiposity is a necessary process; however, it may not be as pleasant. Evaluating fat is, most of the time, uncomfortable and embarrassing for the patient. ${ }^{17}$

The Localized Adiposity Physiotherapeutic Evaluation Protocol created by Meyer et al, is a simple, low-cost, and easy-to-use method that assists in the evaluation and therapeutic planning of the patient with localized adiposity who seeks treatment. This protocol consists of identification, anamnesis, physical examination, measurements, and tests. Ideally, an evaluation should be performed before treatment, with follow-up with reassessments in the middle and at the end of treatment. Basic anamnesis information should be collected, such as main complaint, situational background, eating and social habits (smoking and alcoholism), use of medication, sleep quality, and physical exercise. During the physical examination, the following things are observed: body shape and presence of associated aesthetic dysfunctions (stretch marks, cellulite, tissue flaccidity, skin trophism, muscular strength, and painful sensitivity). In addition, body measurements are also carried out with the use of an adipometer, a dermographic pencil, and tape measure (perimetry). ${ }^{17}$ 


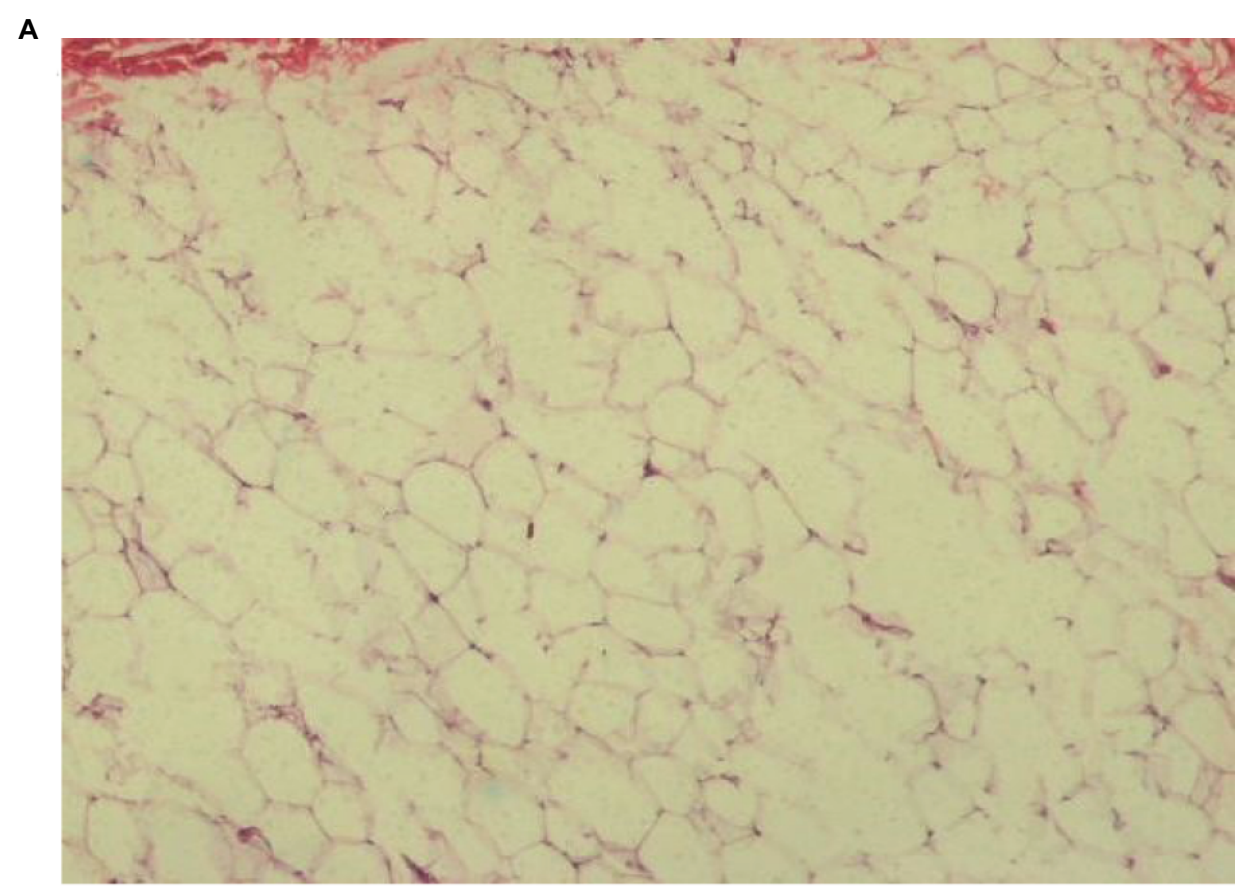

B

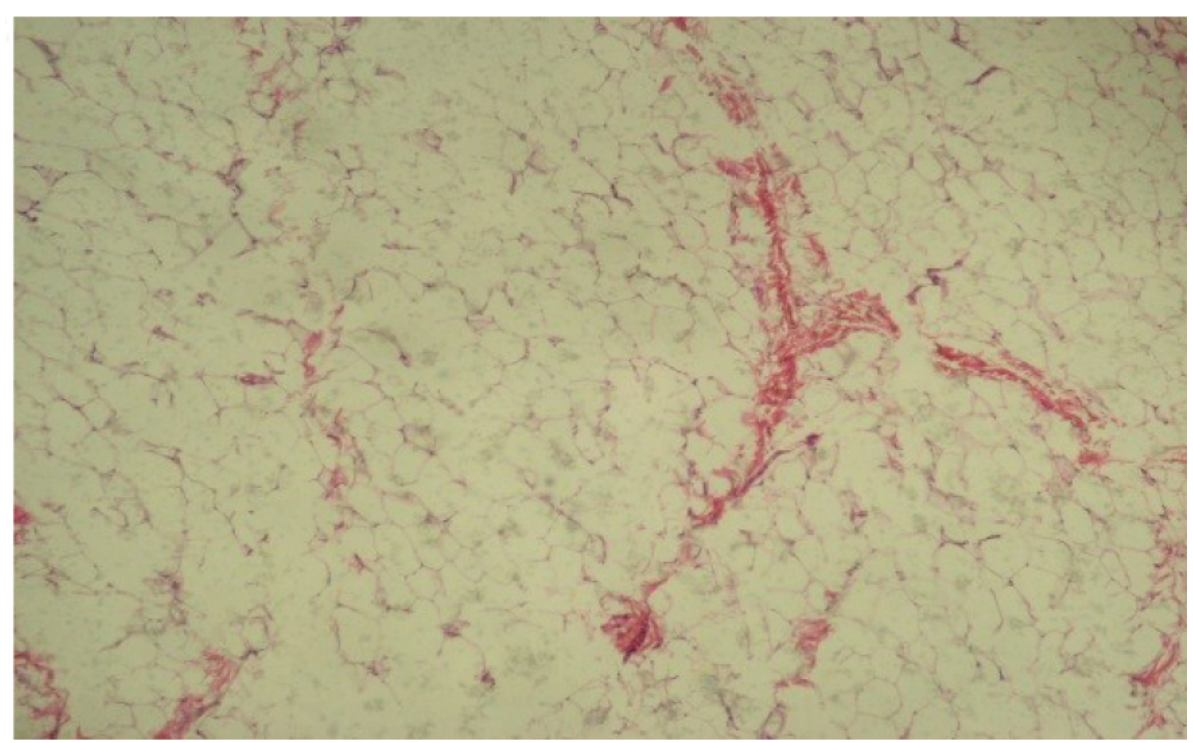

Figure 2 Longitudinal microphotography, H\&E 100× (A) region with areas of adipose tissue destruction; (B) region with formation of fibrous tissue. Abbreviation: H\&E, hematoxylin and eosin.

Specific tests are also performed within The Localized Adiposity Physiotherapeutic Evaluation Protocol protocol, such as the Hip Test and the Abdomen Test, which serve to differentiate localized fat from flaccid skin through gluteal contraction and abdominal contraction, respectively. ${ }^{17-19}$

Other forms of measurement of adipose tissue require more complex investigations, such as ultrasonography and MRI. The photos should serve as an additional analysis resource, and care must be taken when taking the photograph before and after the procedure to ensure standardization of photos in relation to distance, positioning, brightness, etc. ${ }^{10,12,14-16,19,20}$

\section{Risk pathologies for cryolipolysis}

Cryolipolysis is contraindicated in people with cold-sensitive conditions such as Raynaud's Syndrome or any disease based on cryoglobulinemia, cold urticaria, severe varicose veins dermatitis, or loss of skin continuity due to prolonged exposure to the localized cold inducer. The literature also cites some other conditions where there is a positive rheumatoid 
factor (Sjögren's Syndrome, lupus, vasculitis, rheumatoid arthritis, hepatitis C).

The use of cryolipolysis used to be discouraged in patients with cardiovascular disorders, increased cholesterol and liver enzymes, and those with any type of hepatic steatosis-related disease. However, many studies have clarified that there is no change in cholesterol levels, triglycerides, and liver enzymes that point to the risk of steatosis or worsening of such condition; therefore, these do not need to be considered as patient exclusion criteria.

\section{Final considerations}

It is known that although cryolipolysis is now considered a safe and highly effective procedure, the care that must be taken in the selection and preparation of the candidate patient for this treatment are essential for the success of the process and to ensure patient satisfaction and treatment results.

\section{Disclosure}

The authors report no conflicts of interest in this work.

\section{References}

1. Krueger N, Mai SV, Luebberding S, Sadick NS. Cryolipolysis for noninvasive body contouring: clinical efficacy and patient satisfaction. Clin Cosmet Investig Dermatol. 2014;7(7):201-205.

2. Nelson AA, Wasserman D, Avram MM. Cryolipolysis for reduction of excess adipose tissue. Semin Cutan Med Surg. 2009;28(4):244-249.

3. Zelickson BD, Burns AJ, Kilmer SL. Cryolipolysis for safe and effective inner thigh fat reduction. Lasers Surg Med. 2015;47(2):120-127.

4. Kilmer SL, Burns AJ, Zelickson BD. Safety and efficacy of cryolipolysis for non-invasive reduction of submental fat. Lasers Surg Med. 2016;48(1):3-13.
5. Stevens WG. Does cryolipolysis lead to skin tightening? A first report of cryodermadstringo. Aesthet Surg J. 2014;34(6):NP32-NP34.

6. Avram MM, Harry RS. Cryolipolysis for subcutaneous fat layer reduction. Lasers Surg Med. 2009;41(10):703-708.

7. Dierickx CC, Mazer JM, Sand M, Koenig S, Arigon V. Safety, tolerance, and patient satisfaction with noninvasive cryolipolysis. Dermatol Surg. 2013;39(8):1209-1216.

8. Adatto MA, Adatto-Neilson R, Novak P, Krotz A, Haller G. Body shaping with acoustic wave therapy AWT( $\left({ }^{\circledR}\right) / \mathrm{EPAT}\left({ }^{\circledR}\right)$ : randomized, controlled study on 14 subjects. J Cosmet Laser Ther. 2011;13(6):291-296.

9. Ferraro GA, De Francesco F, Cataldo C, Rossano F, Nicoletti G, D'Andrea F. Synergistic effects of cryolipolysis and shock waves for noninvasive body contouring. Aesthetic Plast Surg. 2012;36(3):666-679.

10. Meyer PF, Furtado ACG, Morais SFT, et al. Effects of cryolipolysis on abdominal adiposity of women. Cryo Letters. 2017;38(5):379-386.

11. Stevens WG, Bachelor EP. Cryolipolysis conformable-surface applicator for nonsurgical fat reduction in lateral thighs. Aesthet Surg J. 2015;35(1):66-71.

12. Mostafa MS, Elshafey MA. Cryolipolysis versus laser lipolysis on adolescent abdominal adiposity. Lasers Surg Med. 2016;48(4):365-370.

13. Klein KB, Bachelor EP, Becker EV, Bowes LE. Multiple same day cryolipolysis treatments for the reduction of subcutaneous fat are safe and do not affect serum lipid levels or liver function tests. Lasers Surg Med. 2017;49(7):640-644.

14. Bernstein EF, Bloom JD. Safety and efficacy of bilateral submental cryolipolysis with quantified 3-dimensional imaging of fat reduction and skin tightening. JAMA Facial Plast Surg. 2017;19(5):350-357.

15. Meyer PF, da Silva RM, Oliveira G, et al. Effects of cryolipolysis on abdominal adiposity. Case Rep Dermatol Med. 2016;2016:1-7.

16. Coleman SR, Sachdeva K, Egbert BM, Preciado J, Allison J. Clinical efficacy of noninvasive cryolipolysis and its effects on peripheral nerves. Aesthetic Plast Surg. 2009;33(4):482-488.

17. Mendonca AG, Rodrigues RD, Corradi DP, et al. Protocolo de avaliação fisioterapêutica em adiposidade localizada. Fisioterapia Brasil; 2008.

18. Gouvêa E, Facuri F, Torres R. Estética in Nordeste. 1st ed. Fortaleza: Ceará; 2017.

19. Agne JE. Criolipólise e outras tecnologias no manejo do Tecido Adiposo. 1st ed. Rio Grande do Sul: Santa Maria; 2016.

20. Shane D, Morrison MD. Cryolipolysis: a question of scientific and photographic integrity. Plast Reconstr Surg. 2015;136(6):862-864.
Clinical, Cosmetic and Investigational Dermatology

\section{Publish your work in this journal}

Clinical, Cosmetic and Investigational Dermatology is an international, peer-reviewed, open access, online journal that focuses on the latest clinical and experimental research in all aspects of skin disease and cosmetic interventions. This journal is included on PubMed. The manuscript management system is completely online

\section{Dovepress}

and includes a very quick and fair peer-review system, which is all easy to use. Visit http://www.dovepress.com/testimonials.php to read real quotes from published authors 